\title{
Delay in investigating haematuria
}

\section{Introduction}

Bladder cancer is the most common cause of macroscopic haematuria in the over 40 year age group in Sri Lanka [1]. Delay in initiating treatment may have a profound effect on the survival rate in patients with bladder cancer [2]. In the present study, we investigated the delay between the onset of symptoms and commencement of treatment in patients with macroscopic haematuria in whom it was the presenting symptom, with emphasis on bladder cancer.

\section{Patients and methods}

Between 1 January 2002 and 31 December 2002, 106 consecutive new patients with macroscopic haematuria as the presenting symptom, were prospectively evaluated in our unit. All patients were evaluated with a detailed history, physical examination and appropriate investigations.

We used the following definitions:

Patient delay is the time (days) between first notice of haematuria and seeking medical advice. Doctor delay is the time (months) between the first consultation and the patient's first visit to the urologist at the hospital. Hospital delay is the time (days) between the first urological consultation and the first definitive treatment for the disease. We determined the hospital delay only for bladder cancer patients.

\section{Results}

In all, 106 patients were identified with macroscopic haematuria during the 12 -month period ( 86 males). There were 73 patients over the age of 40 years and 33 under the age of 40 . The mean age was 51.6 years (range 4-94 years, SD 16.5). Fifty eight (54.7\%) patients had painless haematuria and $48(45.3 \%)$ patients presented with painful haematuria. The mean duration of haematuria was 7.5 months (range 1 day to 5 years).

The causes of macroscopic haematuria in our study are given in Table 1. Bladder cancer was the most common cause $(42.5 \%)$ of macroscopic haematuria in the over 40 year age group. Thirty six (34.0\%) patients reported to their doctors on the first day of haematuria. The median patient delay was 14 days (mean 15.3 ; range 1-330). Patient delay for bladder cancer had a median of 12 days (mean 28.6; range 1-330). Seven of 32 bladder cancer patients reported to their doctor on the first day of haematuria. Doctor delay is shown in Table 2. Median hospital delay for bladder cancer patients was 7 days (mean 5; range 1-22) 
Table 1. Causes of macroscopic haematuria in $\mathbf{1 0 6}$ patients

\begin{tabular}{lr}
\hline \multicolumn{1}{c}{ Cause } & Number $(\%)$ \\
\hline - Urological malignancy & $35(33.0)$ \\
Bladder cancer & $32(30.2)$ \\
Renal cell carcinoma & $2(1.9)$ \\
Urothelial tumour of ureter & $1(0.9)$ \\
- Urolithiasis: & $34(32.0)$ \\
Upper urinary tract stone(s) & $29(27.4)$ \\
Bladder stone(s) & $5(4.7)$ \\
- Cystitis & $10(9.4)$ \\
- Benign prostatic hyperplasia & $3(2.8)$ \\
- Undiagnosed & $24(22.6)$ \\
Total & $\mathbf{1 0 6}(\mathbf{1 0 0})$ \\
\hline
\end{tabular}

Table 2. Medical practitioner consulted first by all patients, patients who had bladder cancer and the doctor delay for bladder cancer

\begin{tabular}{lcccccc}
\hline \multicolumn{1}{c}{ Category } & $\begin{array}{c}\text { All cases } \\
\text { number (\%) }\end{array}$ & $\begin{array}{c}\text { Bladder } \\
\text { cancer } \\
\text { number }\end{array}$ & \multicolumn{4}{c}{$\begin{array}{c}\text { Doctor delay* } \\
\text { for bladder cancer } \\
\text { Mean }\end{array}$} \\
\hline $\begin{array}{l}\text { General } \\
\text { practitioner }\end{array}$ & $50(47.2)$ & 13 & 6.8 & 3.5 & $0.5-36$ \\
$\begin{array}{l}\text { Medical } \\
\text { officer OPD** }\end{array}$ & $22(20.8)$ & 7 & 5.8 & 2.0 & $0.33-18$ \\
$\begin{array}{l}\text { Specialist } \\
\text { (Non-urologist) }\end{array}$ & $22(20.8)$ & 8 & 1.4 & 2.0 & $0.25-3$ \\
$\begin{array}{l}\text { Specialist } \\
\text { (Urologist) }\end{array}$ & $6(5.6)$ & 0 & - & - & - \\
$\begin{array}{l}\text { Indigenous } \\
\text { practitioner }\end{array}$ & $6(5.6)$ & 4 & 5.7 & 4.5 & $0.25-7$ \\
Total & $\mathbf{1 0 6}(\mathbf{1 0 0 . 0 )}$ & $\mathbf{3 2}$ & $\mathbf{6 . 5}$ & $\mathbf{3 . 0}$ & $\mathbf{0 . 2 5}-\mathbf{3 6}$ \\
\hline
\end{tabular}

* In months

** Outpatients Department of a state hospital

\section{Discussion}

Macroscopic haematuria is an alarming symptom to a patient, necessitating immediate medical attention. In the present series, bladder cancer was the predominant cause of macroscopic haematuria, affecting $30.2 \%$ of patients. In the over 40 year age group it accounted for $42.5 \%$ of patients with macroscopic haematuria.

The total delay from first onset of symptoms to first treatment can be divided into patient delay, doctor delay and hospital delay. Patients in the UK usually present to their general practitioner (GP) soon after the onset of symptoms (most within one week) and are rapidly referred to a hospital $[2,4]$. The West Midlands Urological Research Group study found a significantly better survival for patients referred to a hospital within 14 days of the onset of symptoms [3]. In the present study, 34\% of patients with macroscopic haematuria reported to their doctors on the first day of noticing haematuria and the median patient delay was only 14 days. Hence, the patient delay is not a significant contributory factor for the total delay in Sri Lanka. The $47 \%$ of patients in this study reported to their GP with the complaint of macroscopic haematuria, and $26 \%$ of these patients were found to have bladder cancer. The median GP delay of 3.5 months is unacceptably long.

In the UK, hospital delay is the most significant cause of the total delay in the diagnosis and definitive treatment of patients with bladder cancer [3-5]. The median hospital delay was 68 days in the West Midlands study [3]. Our unit's policy of fast-tracking haematuria patients over 40 years of age for cystoscopic evaluation, disregarding waiting time, is responsible for the extremely short hospital delay (median 7 days) for bladder cancer.

Most patients in this series reported to their doctors promptly, one third on the first day of haematuria. The long doctor delay may reflect a failure to recognize macroscopic haematuria as a characteristic feature of urological cancer and urolithiasis, and that delay in the diagnosis of malignancy worsens prognosis.

\section{References}

1. Goonewardena SAS, Abeygunasekera AM. Haematuria as the presenting symptom: experience from a tertiary referral centre in Sri Lanka. Ceylon Medical Journal 1998; 43: $156-8$.

2. Wallace DM, Harris DL. Delay in treating bladder tumours. Lancet 1965; 2: 332-4.

3. Wallace DMA, Bryan RT, Dunn JA, Begum G, Bathers S. Delay and survival in bladder cancer. British Journal of Urology International 2002; 89: 868-72.

4. Stower MJ. Delays in diagnosing and treating bladder cancer. British Medical Journal 1988; 296: 1228-9.

5. Gulliford MC, Petruckevitch A, Burney PGJ. Survival with bladder cancer, evaluation of delay in treatment, type of surgeon, and modality of treatment. British Medical Journal 1991; 303: 437-40.

Serozsha AS Goonewardena, Urological Surgeon and UDCA Perera, Senior House Officer, Department of Urology, National Hospital of Sri Lanka, Colombo.

Correspondence: SASG, Tel: +94 11 2770054, e-mail : <sasguro@sltnet.lk> (Competing interests: none declared). 